\title{
The Phenomenology of Sensorimotor Understanding
}

\author{
Ken Pepper \\ Department of Philosophy, University of York, UK
}

\begin{abstract}
This paper draws on Maurice Merleau-Ponty's philosophy to sketch a phenomenological interpretation of sensorimotor understanding. I begin by situating Noë's enactive theory of vision in relation to Husserlian phenomenology. I then raise three related objections to Noë's treatment of sensorimotor understanding in terms of practical knowledge of possibilities for action. Finally, I appeal to Phenomenology of Perception to show how two of its major operative concepts - the 'body schema' and 'sedimentation' - can help to plug the gaps in Noë's account.
\end{abstract}

Keywords: Merleau-Ponty, Alva Noë, body schema, affordances, sensorimotor enactivism

\section{Introduction}

Although Merleau-Ponty's early phenomenology is often invoked in discussions of embodied and enactive approaches to perception, it is seldom the subject of sustained engagement in the sensorimotor theory literature. Appropriation of Phenomenology of Perception is generally limited to the occasional citation of pieces of phenomenological description with the aim of portraying Merleau-Ponty as an early advocate of the enactive approach, without due attention to the wider philosophical project in which those descriptions occur. This has the doubly unfortunate consequence of portraying Phenomenology of Perception as a mere work of descriptive psychology and obscuring possibilities for philosophically interesting disagreement or mutual enlightenment between contemporary sensorimotor theorists and phenomenologists. This paper sketches one path a more satisfying engagement might take, by casting a Merleau- 
Pontian eye over the role of so-called 'sensorimotor understanding' in visual experience. I begin by introducing O'Regan and Noë's notion of sensorimotor understanding and situating it relation to Merleau-Ponty's own philosophical starting point, Husserlian phenomenology. I then present three problems incurred by Noë's characterisation of sensorimotor understanding in terms of practical knowledge of possibilities for action. The decision to focus primarily on the work of Noë rather than O'Regan is motivated by Noë's repeated assertion that his philosophical project is essentially a phenomenological one [e.g. 2004 p.33; 176]. I then turn to Phenomenology of Perception to show how two of its major themes - the 'body schema' and the arguably lesser known 'sedimentation' - can help plug the gaps in Noë's account and form the basis of what Husserl called a 'genetic' phenomenology of sensorimotor understanding.

\section{Object Horizons, Affordances, and Sensorimotor Understanding}

It is tempting to think that only that which imposes on the retinas can be presented in visual experience, but this commits what Merleau-Ponty calls the 'experience error' -the (mis)description of perception in terms of what we come to know upon reflection about its objects at the expense of capturing the original lived experience [2012 p.5]. In fact, though strictly speaking unseen, occluded surfaces and features of objects are given in visual experience as present to one. For example, when I look at a coffee cup on a desk, it is part and parcel of my experience of the cup that it has a reverse side which, though occluded given my current perspective, is present in my immediate environment and potentially visible from an alternative perspective. Phenomenologically speaking, this is just a basic fact about what it is for human beings to see a three-dimensional object as a three-dimensional object. Husserl revisited these phenomena of perspective and presence throughout the development of his phenomenology. In Husserl's terminology, occluded features are experienced as 'co-present' 
[1999 p. 222], because objects are given in perceptual experience as exhibiting the phenomenal feature of horizons; any visual presentation of an object at a particular instant anticipates additional presentations of that object at future instants

[I]n being there itself, the physical thing has for the experiencer an open, indefinite, indeterminately general horizon, comprising what is itself not strictly perceived - a horizon (this is an implicit assumption) that can be opened up by possible experiences. [Husserl 1988 p.23]

We can summarise this Husserlian insight by saying that visual experience has a horizonal structure. ( $\mathrm{Nb}$. To anticipate a potential confusion, it should be noted that 'horizons' enjoys varied usage in the phenomenological tradition. Husserl and Merleau-Ponty sometimes use 'horizons' in an extended sense to encompass not just copresented features of objects, but also what we would now following Gibson [1986] refer to as 'affordances'. This is unfortunate, but the ambiguity owes more to literary convention than a genuine ignorance of the distinction. As I shall be arguing that affordances and the 'general horizons' described in the quote from Husserl above are distinct, I will restrict my usage of 'horizons' to co-presented occluded surfaces and features of objects only, a restriction I shall henceforth enforce via the term 'object horizons'.)

Sensorimotor enactivists share Husserl's enthusiasm for this phenomenon. Noë's rather confusing term for it in Action in Perception is 'virtual presence', but I shall adhere to the original Husserlian terminology throughout. According to Noë's enactive theory of vision, the phenomenon of co-presence owes to the world's being experienced as 'available to perception through appropriate movement' [Noë 2012 p.58, italics removed], and this requires that perceivers possess sensorimotor understanding (also variably referred to as 'sensorimotor knowledge' or 'sensorimotor skill'). Being a perceiver is said to require an implicit grasp of sensorimotor contingencies - the law-like regularities between sensory contents and shifts in perspective brought about through bodily movement and perturbations in one's immediate environment [O’Regan \& Noë 2001 pp.940-3]. This implicit grasp of sensorimotor contingencies is 
held to be a practical, as opposed to propositional, form of knowledge; in Ryle's idiom, it involves knowing-how rather than knowing-that [Noë 2004 pp.117-22, Ryle $2000 \mathrm{Ch}$. II]. On the enactive account, although we do not need to continually move in order to experience co-presence [Noë 2010], we experience co-presence because we know implicitly how to maneuver ourselves in relation to the object in such a way as to bring the occluded side or feature into view.

Noë's characterisation of sensorimotor understanding as practical knowledge of possibilities for action leads him to cash out the horizonal structure of visual experience in terms of Gibsonian affordances. For Gibson, to see an affordance is to directly perceive a familiar object's practical 'value' or 'meaning' [1986 p.127], that is, to see it as suggesting a possible usage which can be taken up in action: a chair affords sitting to a creature capable of sitting, lateral terrain affords walking to a creature capable of perambulation, and so forth. In Gibson's ecological theory of vision, though affordances are 'external' properties of objects, they are nevertheless relational properties- they are 'animal-relative', meaning that their perceptibility depends on the behavioural repertoire of the perceiver [ibid. pp.127-8]. Noë's extreme ecological proposal is that visual experience comprises affordances all the way out

According to the enactive view, there is a sense, then, in which all objects of sight (...) are affordances. To experience a property is, among other things...to experience the object as determining possibilities of and for movement. [Noë 2004. p.106, emphasis in original]

Both Noë and O'Regan tend to equivocate on the issue of whether or not these 'possible movements' need be self-initiated or not, but there is ample textual evidence to suggest that what really differentiates their sort of approach to vision from more traditional cognitivist theorising is an emphasis on self-initiated action. For example, O'Regan is quick to defend his work on vision against a misreading according to which seeing always requires the exercise of a bodily action, but nevertheless states that 'action must potentially play a role' in all perception [O'Regan 2010 p.41]. Noë [2010; 2012] now presents his work on perceptual presence under the moniker of 
'actionism', the rhetoric of which is clearly indicative of an emphasis on self-initiated movement. Elsewhere he tells us, 'Only through self-movement can one test and so learn the relevant patterns of sensorimotor dependence' required to perceive [2004 p.13, italics in original]. And it is surely only in terms of self-initiated movement that we can make sense of his otherwise bewildering comparison of visual experience to 'a kind of dance' [2012 p.130]. In any case, the invocation of Gibson's ecological approach to vision only makes sense within the context of active self-movement, so this reading is not only justified, but necessitated by the claim under consideration.

Following Husserl and Noë, then, I will take it as an undeniable phenomenological fact that object perception is irreducibly horizonal, that is, I will grant that copresence is a basic phenomenal feature of visual experience. What I shall criticise, however, is Noë's claim that the horizonal structure of visual experience can be understood in terms of Gibsonian affordances and the possession of practical know-how. In the next section I outline three related objections to this claim. In the following section, I appeal to Merleau-Ponty's phenomenology to pick up the pieces.

\section{Object Horizons are not Affordances}

There are at least three problems with Noë's attempt to understand object horizons in terms of affordances for action and practical know-how. First, to perceive an affordance is to grasp a visual scene as suggesting possibilities for voluntary behaviour, and not all bodily movement that would bring co-presented features to visual presentation requires volition. Consider again the visual experience of a coffee cup on a desk. The anticipation that the cup has a reverse side would be fulfilled irrespectively of whether or not the movements required to see it were voluntary. Passive, involuntary movements would do the job just as well: I could be pushed into a different spatial position or fall and land with my head on the desk behind the cup, and the percep- 
tual anticipation would still be fulfilled. A less frivolous example would be somebody incapable of voluntary self-movement, perhaps since birth, pushed around the desk in their wheelchair while they happened to be looking at the cup. Cashing out horizons in terms of an implicit grasp of possibilities for action therefore over-specifies the content of sensorimotor understanding. Perceptual sensitivity to the way in which movements of one's body would modify one's current perceptual experience need not require seeing an object as affording possibilities for active self-movement.

It is important to distinguish between action-dependence and movementdependence in perceptual experience. A perceptual experience is action-dependent if and only if it depends for its content or character on the perceiver's knowing how to act in certain ways, that is, if it contains some reference to possible self-initiated movement. Affordances are clearly action-dependent in this sense, for taking up an affordance requires an exercise of volition. An experience is merely movementdependent if it involves being sensitive to sensorimotor contingencies without associating those contingencies with possibilities for self-initiated movement. Horizons are certainly movement-dependent, but they are not thereby action-dependent. Hence, there is conceptual space between affordances -which presuppose volition, and object horizons, which do not, which gives us good grounds for refraining from equating the two. This is not to say that object horizons are not explicable in sensorimotor terms. The sensorimotor theorist can continue to hold that it is necessary for experiencing horizons that one's visual system be sensitive to movements of one's body and nearby objects. The crucial point is that this does not by itself license Noë's much stronger claim that object horizons are affordances.

A second problem with equating horizons with affordances concerns the psychological development of vision and agency. There are empirical grounds for holding that horizons are developmentally prior to affordances. Consider Held and Hein's [1963] famous 'kitten carousel' experiment. In contrast to a popular misconception the experiment concerned visually guided behaviour, not visual experience. For three hours daily ten pairs of neonatal kittens were placed in apparatus resembling a fairground carousal: a circular box with a two-pronged rotating arm fixed at the centre. 
At one end of the rotating arm, the 'active' kitten of the pair was attached to a harness with its feet in contact with the ground so that it could control its own locomotion. The 'passive' kitten was placed in a box with its head held in a fixed position and suspended from the other end of the rotating arm so that it could see the inside of the apparatus but not move around freely (although it could still move its own eyes). By walking, the active kitten pulled the passive kitten around the carousel, so while both sets of kittens were exposed to the same patterns of movement and visual stimuli, only the active kittens' movements around the apparatus were self-initiated. Held and Hein found that the active kittens avoided visual cliffs, put out their paws to brace themselves when picked up and placed on a surface, and displayed avoidance behaviour to looming objects, while the passive kittens did not, though their responses did normalise within forty-eight hours. Unsurprisingly, they conclude that 'self-produced movement with its occurrent visual feedback is necessary for the development of visually guided behaviour' [Held \& Hein 1963 p.875].

The passive kittens' normal pupillary reflexes, healthy eyes, and the quickness with which they adapted to visually guided behaviour indicate their visual sense was not impaired by lack of self-movement; rather their ability to coordinate voluntary movement with their visual experience was temporarily hindered [ibid. p.875-6]. Noë interprets the passive kittens' failure of the visual cliff task as evidence for a lack of depth perception [2004 p. 234 §9]. Given their intact visual system this seems implausible, and such an interpretation incurs the potentially intractable, perhaps even paradoxical, problem of explaining how a creature could see three-dimensional objects in their immediate environment without experiencing depth. This would be tantamount to asserting that despite their fully-functioning visual systems, the passive kittens see the cliff in two-dimensions - an ad hoc stipulation if ever there was one. A more conservative explanation suggested by Kinsbourne [1995 pp.215-6] is that the cliff looks the same to both kittens, but only the active kittens have developed the association between the appearance of a flat surface and the feel of solid terrain under their paws.

Continuing to grant that object horizons are a basic, irreducible feature of visual experience, engaging in a spot of feline 'hetrophenomenology' (see Dennett [1991] 
pp.72-85] allows us to draw the following moral: the passive kittens perceived objects as objects, and therefore experienced horizons, but, unlike the active kittens, could not perceive affordances; visual cliffs and looming objects did not 'negatively afford' avoidance (see Gibson [1986] p.137), the approaching floor did not afford pawextension, etc. The ability to see affordances developed as their spatial vision and capacities for bodily action were allowed to integrate as they otherwise would have naturally. Hence, there is good reason for thinking that horizons are phenomenologically more basic than affordances as the former can apparently exist in the absence of the latter (but not vice versa), and also that the ability to see affordances requires some additional development over and above a more primitive capacity to experience object horizons. Again, this is not to say that the passive kittens' visual experience cannot be understood in sensorimotor terms. They were, after all, exposed to the same patterns of movement-dependence as the active kittens, only their movement was almost entirely involuntary. The point is that mere visual sensitivity to movement does not equate to an ability to grasp affordances for action.

A third problem with equating horizons with affordances stems from an inconsistency in the attribution of practical knowledge to subjects incapable of performing the required bodily movements themselves. While Noë does not claim that severe restrictions on a perceiver's ability to act would result in blindness (which would be patently and demonstrably false), he does claim that the preservation of normal vision in the paralysed owes to the retention of sensorimotor understanding

Paralysis is certainly not a form of blindness...Even the paralysed, whose range of movement is restricted, understand, implicitly and practically, the significance of movement for stimulation. They understand, no less than those who are not disabled, that movement of the eyes to the left produces rightward movement across the visual field, and so forth. Paralysed people can't do as much as people who are not paralysed, but they can do a great deal; whatever the scope of their limitations, they draw on a wealth of sensorimotor skill that informs and enables them to perceive. [Noë 2004 p.12] 
Noë frequently describes sensorimotor understanding as a form of nonpropositional practical knowledge, or skill [ibid. pp.117-22]. On a standard conception of practical knowledge or skill, knowing-how to $\phi$ necessitates being able to $\phi$. This conception of practical knowledge is certainly what Ryle had in mind in his original articulation of his knowing-how/knowing-that distinction, as he argued that skills are acquired dispositions to act [2000 p.33]. For example, if I cannot play the guitar to a certain standard, then I do not possess the skill of guitar playing: I do not know how to play the guitar in the required sense. If an injury requiring physical rehabilitation renders me unable to execute the required movements I lose my practical knowledge, even if I can describe quite well what it is I am supposed to do with the instrument to produce the desired sounds. Skills are, in Merleau-Ponty's words, 'knowledge in the hands' [2012 p. 145], and this is why we do not say of an athlete past her prime that she has retained her skill even though she can no longer compete, but rather that she can no longer compete because age has deprived her of her skill. As the following quotation makes clear, this Rylean conception of practical knowledge is explicitly endorsed by Noë ${ }^{1}$

I would have thought that if a ski instructor can't do the jump, then she doesn't know how to do it... She knows how the jump is done, but not how to do it. Sadly the same is true of the pianist [who has lost an arm]. He may retain all sorts of cognate [propositional] knowledge (...) but when he lost his arms, he lost his know-how. For the knowledge was, precisely, armdependent. [Noë 2004. p.121]

The problem for Noë's sensorimotor enactivist should now be obvious: if the possession of practical knowledge is dependent upon or identical to an ability to act, then

\footnotetext{
${ }^{1}$ Ryle's knowing-how/knowing-that distinction has been challenged by Stanley and Williamson (2001), but given Noë's endorsement of the distinction I shall grant it for the sake of argument. My intuition on this matter is that Stanley and Williamson's critique, which concerns the logical form of knowledge ascription sentences, rather misses the point of Ryle's original distinction, which is more phenomenological than logical. Ryle himself suggests such an interpretation when he writes that The Concept of Mind as 'could be described as a sustained essay in phenomenology, if you are at home with that label' (2009 p.196).
} 
it is nonsensical to attribute practical knowledge of possibilities for action to those in whom such abilities are lacking.

Locked-in syndrome is instructive in this regard. The 'classical' variation of locked-in syndrome involves complete paralysis apart from blinking and limited vertical eye movement [Bauer, Gersenbrand and Rumpl 1979]. ${ }^{2}$ Sufferers of the syndrome can communicate using systems of blinks and vertical eye movements and with the help of various eye-tracking technologies [Laureys et al 2005], so rather a lot is known about their experience from firsthand reports. People with locked-in syndrome retain full visual consciousness and their intellectual capacities remain untouched. Indeed the condition's defining characteristic is the patient's being 'literally locked inside his body, aware of his environment but with a severely limited ability to interact with it' [Patterson \& Grabois 1986 p.758]. Although locked in syndrome can sometimes negatively affect visual attention [Smith \& Delargy 2005 p.406], one patient goes so far as to describe his vision as 'normal, if not enhanced' [Chisholm \& Gillet 2005 p.94]. As they see perfectly well we can say without controversy that locked-in perceivers' experience has a horizonal structure. Of course, sensorimotor enactivists need not, do not, and given their phenomenological starting point cannot, deny this. But it is wrongheaded to explain the locked-in subject's visual experience in terms of practical knowledge of how 'movement of the eyes to the left produces rightward movement across the visual field' given that, on Noë's own account, their inability to perform these movements renders incoherent the attribution of the practical knowledge required to make them. This goes a fortiori for more complex interactions. The locked-in patient does not know how to maneuver their body around an object in the sense of having the required skills; were they miraculously cured they would need to reacquire them through practice and physiotherapy. Practical knowledge is therefore just the wrong sort of thing to account for object horizons.

2 Classical locked-in syndrome differs from 'incomplete' and 'complete' variations of the condition. With incomplete locked-in syndrome, a very small amount of additional motor control is preserved, while paralysis in the complete variation extends even to blinking and vertical eye movement (Bauer, Gersenbrand and Rumpl 1979). 
At this point, the following question becomes pertinent: If seeing an affordance requires practical know-how, what are we to say of the perception of affordances for the locked-in perceiver? It would be wildly counterintuitive to suggest that locked-in syndrome patients, who have lost almost all their practical knowledge, thereby cannot see affordances. Having been accustomed to living a life of practicality, and given the full preservation of their intellectual and visual capacities, it would be ad hoc and implausibly farfetched, not to mention offensive, to attribute to them an impoverished consciousness whereby they no longer see chairs as for sitting, doors as for opening and closing, coffee cups as for filling and drinking from, etc. Their visual experience is not that of a human equivalent of Hein and Held's passive kittens. We must therefore reject not only the conflation of horizons with affordances, but also the implied conflation of the capacity to see affordances with the possession of practical knowhow. What is needed is a better philosophical framework in which to make sense of sensorimotor understanding.

\section{Motor Signification, Sedimentation and the Body Schema}

These are the facts to be accounted for: object horizons are not Gibsonian affordances, but through the garnering of practical knowledge, they may be 'upgraded' (so to speak) to affordances. But the practical 'value' which the objects of vision have for the perceiver who possesses and exercises the relevant practical know-how - affordances - persists even after this know-how has been lost. The enactivist project is therefore hampered by Noë's restricted conceptual toolkit. Phenomenology of Perception gives us the additional tools needed to untangle the knots in which Noë's sensorimotor enactivist ties herself by attempting to conceive of sensorimotor understanding solely in terms of Rylean practical know-how and Gibsonian ecological psychology. This requires some preliminary exposition on the aim of phenomenology considered not as a subject matter, but as a discipline.

Phenomenological philosophy is personal-level analysis par excellence, but there is considerably more to it than introspective reports on the content or character of psychological states. Husserl's philosophical project gradually evolved from 'static' into 'genetic' phenomenology, and Merleau-Ponty's Phenomenology of Perception sits squarely in the latter category. Static phenomenology describes experience in terms of hypostatised appearances. Genetic phenomenology goes further, and attempts to trace 
the origins of these appearances in lived experience. Alternatively put, we can say that while genetic phenomenology aims to uncover the structures of consciousness through which appearances are formed or, in phenomenological jargon, 'constituted', static phenomenology is limited to the description of its end products. Interestingly, Noë, who takes himself to be 'investigating the phenomenology of perceptual experience' [2004 p.33], echoes Husserl's move from static to genetic phenomenology when he says 'the task of phenomenology ought to be not so much to depict or represent or describe experience, but rather to catch experience in the act of making the world available' [ibid. p.176]. It is fitting, therefore, that the shortcomings of Noë's account of sensorimotor understanding can be rectified by adopting a geneticphenomenological approach, that is, by going beyond the description of perceptual states in order to uncover the subjective operations through which such states come to be constituted in lived experience. Two Merleau-Pontian concepts are indispensable in this regard: the body schema and sedimentation.

In contrast to a percept or mental representation of one's own body, the body schema is Merleau-Ponty's term for the integrated system of pre-reflective bodily capacities that structure perceptual experience. The notion of a body schema has received considerable attention in contemporary cognitive science thanks to the work of Shaun Gallagher who, following Merleau-Ponty's lead, champions a distinction between body schema and body image. ${ }^{3}$ Though Merleau-Ponty would certainly agree with Gallagher that the body schema should be distinguished from any mental state which has the body as its object, the body schema has for Merleau-Ponty an existential significance over and above its being a 'system of sensory-motor processes that constantly regulate posture and movement that function without reflective awareness or the necessity of perceptual monitoring' [Gallagher 2005 pp.37-8]. As MerleauPonty puts it, the body schema is not itself an appearance or an object of thought, but a 'law of constitution' [2012 p.101], meaning that it conditions the ways in which things appear to the perceiver. The body schema is therefore indispensable to a genetic phenomenological analysis of embodied perceptual experience. Recall Gibson's characterisation of affordances as 'animal relative'. The notion of a body schema further illuminates this point. It is by virtue of having a body schema that objects can afford usage and one's environment can take on a practical significance, because the way in which a subject can interact with their environment is relative to the range of possible actions permitted by their specific bodily morphology. A body schema is therefore a precondition of the formation of affordances. This is the meaning of Merleau-Ponty's remark that 'my own body is the primordial habit, the one that conditions all others and by which they can be understood' [ibid. p.93].

Crucially, the body schema is adaptable. By honing skills and acquiring new habits, it can be 'reworked and renewed' [ibid. p.143], and this endows the perceiver's 'A body image consists in a system of perceptions, attitudes, and beliefs pertaining to one's
own body. In contrast, a body schema is a system of sensory-motor capacities that function
without awareness or the necessity of perceptual monitoring.' (Gallagher 2005 p.24) 
experience with a uniquely bodily kind of meaning which Merleau-Ponty calls 'motor signification' [ibid p. 113]. Though it is rather tricky, particularly for an analytically trained philosopher, to define or articulate the idea of 'bodily meaning', an example of the body schema's contribution to lived experience should help to clarify what Merleau-Ponty means by this. For expert musicians, perceptual encounters with their instrument of choice are significant in a way in which the non-players' perception of the same instrument are not. For example, a skilled guitarist has at her disposal a certain 'muscle memory' of (inter alia) various chord shapes, picking techniques and scale patterns lacking in non-musicians who are nevertheless perfectly capable of performing similar finger movements. Consequently, guitars are perceived in a more meaningful way by the guitarist - they draw on a richer sensorimotor understanding alien to a perceiver lacking this enriched motor signification. The non-guitarist knows (in the propositional sense of 'knows' - knowing-that) very well what the guitar is for, and might even know something of how it is played, but the guitar does not afford playing for them in the concrete sense experienced by the skilled player for whom the guitar represents a genuinely possible motor project. The same goes, mutatis mutandis, for other forms of skilful sensorimotor interactions. As a non-driver, the interior of a car is mysterious to me in a way which invites laughter from my road-ready friends even though I have ridden shotgun countless times, and a recent trip abroad served as a lesson in how, despite comprehending and obeying the instructions of helpful local residents, my lack of familiarity with foreign methods of public transport amounted to a kind of behavioural illiteracy. Doubtless we can all recall similar experiences where one struggles to 'interpret' one's environment while others negotiate it effortlessly (the reader is invited to think of their own examples). The difference lies not between two different bodily morphologies, but between the manner and degree to which the same surroundings call for different kinds of engagement. It is by virtue of the body schema and its adaptability that we are geared into our environment in such a way that it makes sense to us. Merleau-Ponty's notion of the body schema therefore provides insight into the phenomenological constitution of Gibsonian affordances, as well as helping to make sense of Gibson's own construal of affordances as both properties of external objects and visible 'values or meanings' [1986 p.127].

With this in mind, we can turn to our second key Merleau-Pontian concept. Normal (i.e. typically developed and non-pathological) subjects can integrate prior mental operations into their behaviour in such a way as to alleviate the need for any rehearsal of the reasoning behind them. Merleau-Ponty's term for this is sedimentation

These acquired worlds which give my experience its secondary sense, are themselves cut out of a primordial world which grounds the primary sense of my experience. Similarly there is a "world of thoughts", a sedimentation of our mental operations, which allows us to count on our acquired concept and judgements, just as we count upon the things that are there and that are given as a whole, without our having to repeat their synthesis at each moment. [2012 p.131] 
Merleau-Ponty's discussion of language provides a handy illustration of sedimentation at work [see 2012 pp.179-205]. Learning the correct way to use a word, coining a phrase, or adopting a manner of talking in line with a newly acquired attitude (such as moderating one's language for the sake of political correctness) are initially the outcome of a creative thought processes through which these habits are constituted. Merleau-Ponty calls this spontaneous or expressive use of language, 'speaking speech'. With practice, the speaker comes to utilise the new linguistic device without needing to remind themselves of the reasoning behind their wording, sometimes having even forgotten it entirely. We can forget the origin of a phrase or the process through which we learned to use it while continuing to routinely deploy it correctly. Merleau-Ponty calls this sedimented (sic) linguistic usage, 'spoken speech'. MerleauPonty sometimes presents spoken speech as a derivative, secondary and therefore inferior or 'inauthentic', form of linguistic communication (or at least he does so in Phenomenology of Perception), but we need not accept this, as the two are mutually grounding. Though sedimented spoken speech is born of speaking speech, spontaneous speaking speech cannot occur ex nihilo, as a novel linguistic coinage presupposes an extant set of word meanings and connotations to be modified and re-appropriated, and against which the novel contribution of a new linguistic creation can be understood (see Baldwin [2007] for criticism of Merleau-Ponty along these lines). Hence, building up the layers of meaning through which subjects engage with the world and each other, rests on a 'double moment of sedimentation and spontaneity' [MerleauPonty 2012 p.132] - the formation of new modes of self-expression and communication within the confines of established linguistic practices.

Returning now to the three problems with Noë's account of sensorimotor understanding outlined in the previous section, and bearing in mind the discussion of the body schema above, my modest suggestion is that similar Merleau-Pontian morals apply to motor significations as to linguistic meaning. Once a perceiver has acquired a piece of practical knowledge - a skill - through an adaptation of their body schema, the perceived world gains for them a new motor signification and the perception of a novel affordance is made possible. However, just as we continue to use and understand 'spoken speech' without recollection of the creative 'speaking speech' through which it was constituted, we can continue to grasp the motor signification of a familiar object once the skilful know-how from which it originates has been lost.

With this genetic phenomenological framework in place, we are now poised to supplement Noë's account of sensorimotor understanding and deal with my three objections. Contra Noë, object horizons are not themselves affordances for action. Keeping Held and Hein's passive kittens as our example, we may say that the ability to perceive affordances - to perceive objects in one's environment as exhibiting a motor signification- is the product of the development of practical know-how via adaptations of one's body schema. This is why despite already being able to see, the passive kittens did not grasp affordances until they had honed the relevant bodily skills. Hence, the perceptual meaningfulness of affordances is constituted (in the phenomenological sense of 'constitution' -as coming to appear as such) through skilful 
sensorimotor interactions, of which the body schema is the vehicle. Now recall the locked-in syndrome patient, for whom the practical knowledge or skill required to take up an affordance is lost. Their meaningful relationship with their visual world their system of motor significations - is not lost, despite their deficit, because for them affordances are already constituted - the bodily meaning of their familiar environment is sedimented - although the opportunity to form new motor significations is largely closed to them due to their severely restricted possibilities for novel sensorimotor interactions through which new motor significations could be constituted.

In closing this section, two additional passages from Phenomenology of Perception will serve to further illustrate the multi-level conception of meaningful sensorimotor understanding discernable in Merleau-Ponty's work that is lacking in Noë's. The first recalls Merleau-Ponty's notion of the 'intentional arc' from his first book, The Structure of Behaviour. The second comes from his discussion of phantom limbs

[T] he life of consciousness - epistemic life, the life of desire, or perceptual life - is underpinned by an "intentional arc" that projects around us our past, our future, our human milieu, our physical situation, our ideological situation, and our moral situation, or rather, than ensures that we are situated within all these relationships. [ibid. p.137]

What refuses the mutilation or the deficiency in us is an I that is engaged in a certain physical and inter-human world, an I that continues to tend toward its world despite deficiencies or amputations and that to this extent does not de jure recognise them. The refusal of the deficiency is but the reverse side of our inherence in a world, the implicit negation of what runs counter to natural the movement that throws us into our tasks... to have a phantom limb is to remain open to all of the actions of which the arm alone is capable and to stay within the practical field one had prior to the mutilation. [ibid. pp.83-4]

The locked-in patient's sensorimotor understanding, though initially the product of practical knowledge, no longer depends for its continued existence on bodily skills, but rather inheres in their visual experience as a sedimented 'projection' of value or, to use a less extravagant phrase, an established way of seeing informed by past experience of interactions with the world. And just as the amputated arm survives for the amputee as a phantom so long as they continue to live through their familiar situation, with all the established affordances they have built up through the skilful use of their now-absent limb, the locked-in perceiver continues to 'project around them their past...human milieu... and physical situation' and thereby preserve the meaningful structure of their perceptual experience. There is therefore what might be described as a 'historical' dimension to the phenomenon of sensorimotor understanding which cannot be adequately captured by the language of commonsense psychology and ecological optics, to which Merleau-Ponty's phenomenology gives voice. And in so doing, it dissolves the worries incurred by Noë's untenably impoverished account of the phenomena. 


\section{Conclusion}

I have argued that Noë's account of sensorimotor understanding suffers from deficiencies and inconstancies which Merleau-Ponty's early phenomenology is equipped to rectify, albeit at the expense of incurring an inflated conceptual inventory which potentially carries its own distinct set of philosophical problems. While Noë is certainly correct that 'the task of phenomenology ought to be...to catch experience in the act of making the world available' [2004 p.176], this requires explicating not just how perceivers 'bring the world forth' [2012 p.14] by applying their sensorimotor understanding in experience, but also what it is to be embodied and situated in such a way as to make such understanding possible in the first place, and to sustain the meaningful structure of perceptual experience to which it give rise. These questions, though not necessarily beyond the scope of cognitive science, are fundamentally existential ones, and the beginnings of answers to them are only sketched here. The sensorimotor theorist, who, like Noë, aspires also to be a phenomenologist, has their work cut out for them.

\section{$\underline{\text { References }}$}

1. Baldwin, T.: Speaking and Spoken Speech. In: T. Baldwin ed. Reading Merleau-Ponty, Routledge, London pp.87-104 (2007)

2. Bauer, G., Gerstenbrand, F. and Rumpl, E.: Varieties of the Locked-In Syndrome. Journal of Neurology 221: 2 pp.77-91 (1979)

3. Chisholm, N. and Gillett G.: The Patient's Journey: Living With Locked-In Syndrome British Medical Journal 331 pp.94-7 (2005)

4. Dennett, D.: Consciousness Explained. Penguin, London (1991)

5. Gallagher, S.: How the Body Shapes the Mind. Oxford University Press, Oxford (2005)

6. Gibson, J.: The Theory of Affordances. In: The Ecological Approach to Visual Perception. Psychology Press, NJ pp.127-43 (1986) [1979]

7. Held, R. and Hein, A.: Movement-Produced Stimulation in the Development of Visually Guided Behaviour. Journal of Comparative and Physiological Psychology 56: 5 pp.872-6 (1963)

8. Husserl, E.: Cartesian Meditations. Trans. D Cairns. Kluwer, Dordrecht (1988) [1950]

9. - Horizons and the Genesis of Perception. Trans. A. Steinbock. In: D. Welton ed. The Essential Husserl. Indiana University Press, IN pp.221-33 (1999)

10. Laureys, S., Pellas, F., Van Eeckhout, P., Ghorbel, S., Schnakers, C., Perrin, F., Berrê, J., Faymonville, M., Pantke, K., Damas, F., Lamy, M., Moonen, G. and Goldman, S.: The 
locked-in syndrome: what is it like to be conscious but paralysed and voiceless?. Progress in Brain Research 150 pp. 495-511 (2005)

11. Merleau-Ponty, M.: The Structure of Behaviour. Trans. A. Fisher. Methuen, London (1965) [1942]

12. - Phenomenology of Perception. Trans. D. Landes, London: Routledge, London (2012) [1945]

13. Noë, A.: Varieties of Presence. Harvard University Press, MA (2012)

14. - Vision without Representation. In: N. Gangopadhyay, M. Madary, and F. Spicer eds. Perception, Action, and Consciousness. Oxford: Oxford University Press pp.245-56 (2010)

15. - (2004), Action in Perception MA: MIT Press

16. O'Regan, J.: Explaining What People Say About Qualia. In: Gangopadhyay, Madary, and Spicer pp.31-50 (2010)

17. - $\quad$ and Noë, A.: A Sensorimotor Account of Vision and Visual Consciousness. Behavioural and Brain Sciences 24 pp.939-1031 (2001)

18. Patterson, J. and Grabois, M.: Locked-in syndrome: a review of 139 cases. Stroke 17 pp.758-64 (1986)

19. Ryle, G.: Phenomenology versus 'The Concept of Mind'. In: Critical Essays: Collected Papers Volume I, London: Routledge pp.186-204 (2009)

20. - The Concept of Mind. Penguin, London (2000) [1949]

21. Smith, E. and Delargy, M., Locked-in syndrome', British Medical Journal 330 pp. 406-9 (2005)

22. Stanley, J. and Williamson, T.: Knowing How. Journal of Philosophy 98: 8 pp.411-44 (2001) 